\title{
Peculiarities of contemporary surface spore-pollen spectra from southern Siberia (Tyva and Khakassia republics)
}

\author{
Tatiana Blyakharchuk
}

Institute for monitoring of climatic and ecological systems of Siberina branch of Russian Academy of Science (IMCES SB RAS). Russia. Tomsk. Akademicheski ave. 10/3, e-mail: tarun5@rambler.ru

Received: 22 April 2017/Accepted: 31 May 2017

\begin{abstract}
In mountains and in intermountain depressions in the south of Western Siberia 31 contemporary (subrecent) spore-pollen spectra were collected with aim to reveal how adequate the composition of spore-pollen spectra reflects vegetation types in study area. It was found that pollen spectra from dry steppe of Tyva are characterized by dominance of Artemisia and Chenopodiaceae pollen, but more north located steppe of Khakassia - by abundance of Poaceae pollen among herbs and by considerable amount of tree pollen, mostly Betula and Pinus sylvestris. A high mountain spore-pollen spectra in Tyva are differed by dominance of Poaceae pollen and increased amount of Cyperaceae pollen with small amount of tree pollen. Spore-pollen spectra of mountain taiga are dominated by tree pollen of Pinus sibirica. Spectra with relic composition combining abundance of Artemisia pollen with increased amount of Picea and Larix pollen were found on the tops of Tannu-Ola ridge in south Tyva. The described features of modern spore-pollen spectra reflect real peculiarities of vegetation in places were these samples were collected including larch-spruce forest alternated with steppe parches on tops of Tannu-Ola ridge. Mathematical method of unconstrained cluster analysis fully conforms the grouping of modern pollen spectra according to vegetation types and hence supports the idea that spore-pollen spectra from mountain areas reflect accurately the vegetation types and composition of local plant communities.
\end{abstract}

Keywords: pollen, spores, subrecent pollen spectra, Siberia, vegetation.

\section{Introduction}

Investigation of surface (subrecent) spore-pollen spectra is important for palaeogeographic research. On the base of subrecent pollen data can be reconstructed past vegetation cover and climate using palaeopollen data by method of biomisation (Prentice et al. 1996). Moreover the subrecent pollen data together with modern climatic parameters in points of collected pollen spectra can be used for quantitative palaeoclimatic reconstructions by method of "best modern analogues" applied to palaeopollen data (Overpeck, Webb III \& Prentice 1985; Guiot 1990; Nakagava et al. 2002). For such research the subrecent spore-pollen data from regions are very important, especially for regions with diverse landscapes and complex vegetation cover. One of such regions - it is mountains of southern Siberia, for which very scarce data on subrecent sporepollen data is published (Kunes et al. 2008). It is one of the rare regions on the Earth where natural vegetation cover survived. In spite of partial logging of mountain forests in the past, and attempts to plug steppe areas during Soviet time the contemporary vegetation of this region is represented by natural plant successions depending on local and regional climates, altitude and types of soil. The purpose of our research consists in more detailed study of relationships between composition of modern spore-pollen spectra and mother vegetation types, in order to get new knowledge, which can be used during interpretation of palaeopollen data in this region. 


\section{The study area}

Khakasia and Tyva republics are located in the Altai-Sayan mountain region $50^{\circ}-55^{\circ} \mathrm{N}, 85^{\circ}-95^{\circ} \mathrm{E}$ to the south of West Siberian Plain and Central Siberian Plateau, where cool humid temperate-continental climate of Siberia meets with arid sharp continental-climate of Central Asia. Vegetation cover of study area reflects north-south climatic gradient as well as north-south decrease of precipitation and increase of continentality of climate. These gradients are superimposed on mountain relief, which causes formation of altitudinal belts of vegetation from steppe and dry steppe in intermountain depressions to mountain forests, sublapine, alpine and tundra vegetation on mountain slopes and tops. The feature of southern Tyva vegetation - spreading of tundra-steppe vegetation on high altitudes and gradual decline of mountain forests belt due to increased aridity and continentality of climate. Diversity of landscapes and climates in study region promote to spreading of contrast types of vegetation. Mountain forests composed by larch (Larix sibirica Mill.), Siberian pine (Pinus sibirica Du Tour) and fir-tree (Abies sibirica Ledeb.) are spread on mountain depending on slope exposition and moisture availability. Birch (Betula pendula Roth.), spruce (Picea obovata Ledeb) and larch grow along river valleys and birch and Scot's pine (Pinus sylvestris L.) forests spread on a piedmonts of the mountains. A relic type of vegetation composed by spruce-larch forest alternated with parches of Artemisia steppe we met on the topes of TannuOla Ridge in southern Tyva. On the contrary, real and dry steppe vegetation is spread on intermountain depressions, some of which, for example Tyva depression, are high elevation steppe with height above sea level up to $900 \mathrm{~m}$. According to north-south climatic gradient a meadow steppe of north Khakasia changes to real Artemisa-grass steppe in south Khakasia and to dry and desert-steppe in the south of Tyva republic on the boundary with Mongolia.

\section{Methods}

In order to study modern spore-pollen spectra of all landscape diversity in study region, we collected for pollen analysis a series of 31 surface samples by method of moss polsters (Canňellas-Bolta et al. 2009) from different vegetation types and from different elevation in mountains and intermountain depressions of Tyva and Khakassia republics. Detailed geobotanical descriptions of vegetation cover in sites of collecting of surface pollen spectra were performed. In places where mosses were absent (steppe and desert vegetation) the surface detritus was collected. In the laboratory samples were chemically treated by traditional alkaline and acetolisis methods with application of HF treatment in case of mineral contamination. All samples including detritus samples from desert-steppe contained rich complex of well preserved pollen and spores. During pollen analysis in general 300-600 palynomorphs

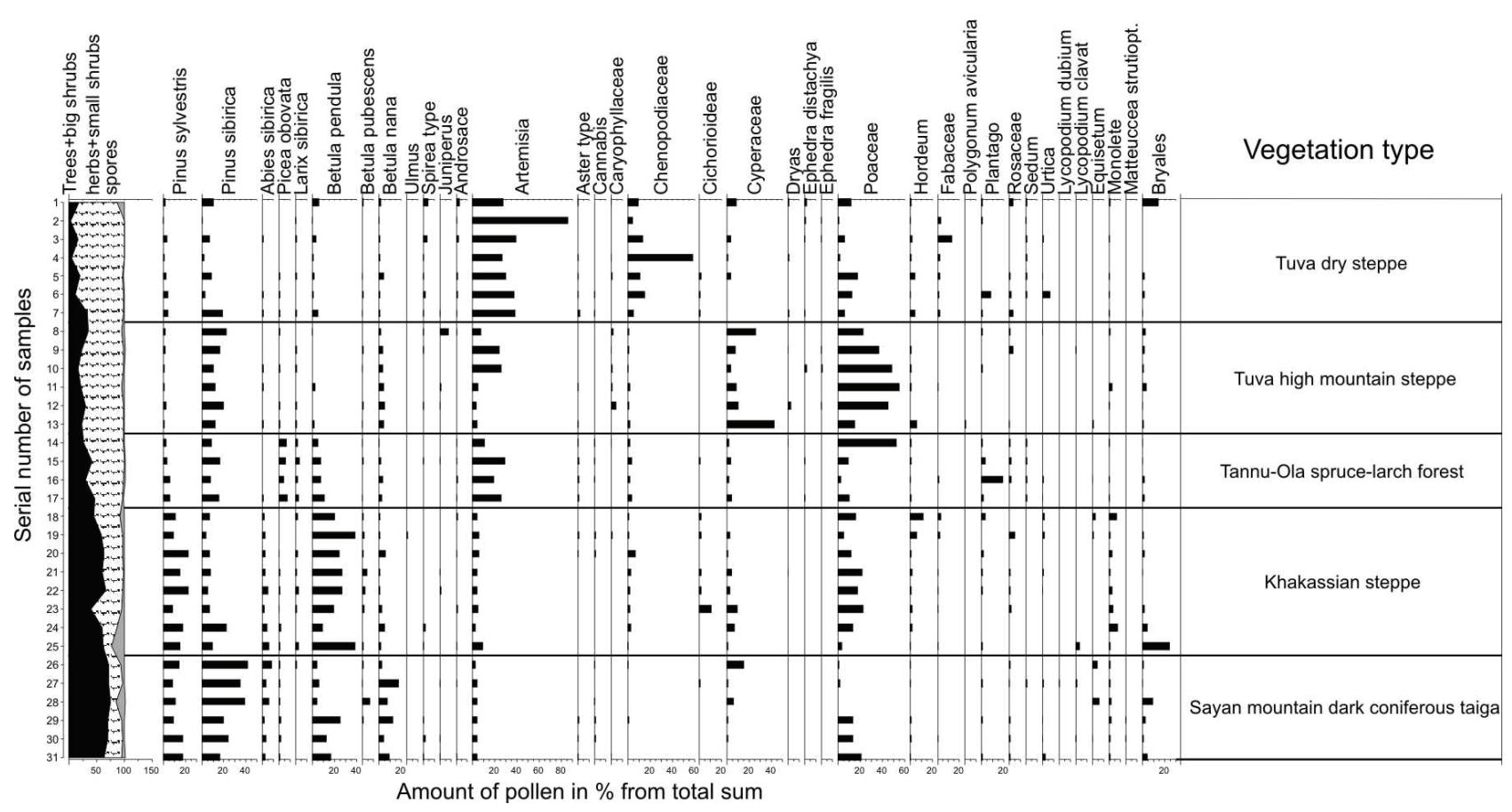

Figure 1. Contemporary surface spore-pollen spectra from Tyva and Khakasia republics 
were recognized and counted with use of light microscope under magnification $400 \mathrm{X}$.

\section{Results and discussions}

Visual ranging of contemporary spore-pollen spectra according to region, altitude and type of vegetation demonstrates very well marked out groups of spectra (Fig. 1). These groups reflect following local types of vegetation (from top of diagram to bottom): Tyva dry steppe; Tyva high mountain steppe; Tannu-Ola spruce-larch mountain forest; Khakassian meadow steppe; Sayan Mountain forests.

Pollen spectra of Tyva dry steppe differ from pollen spectra of Tyva high mountain steppe by dominance of Artemisia and Chenopodiaceae pollen. Something less is amount of grass (Poaceae) pollen and in very small amount presents tree pollen (Fig. 1). Among tree pollen only Pinus sibirica and Pinus sylvestris was found. Among mesophilous coniferous tree species only single pollen grains of Picea obovata were found in separate samples and no one pollen grain of Abies sibirica.
This is interesting that surface pollen spectra of high mountain areas of Tuva Republic differ by dominance of Poaceae pollen in combination with sedge pollen (Cyperaceae) and pollen of dwarf birch (Betula nana). This is in agreement with high mountain vegetation composition in Tyva. The other noticeable feature of high-mountain surface pollen spectra of Tyva Republic - it is rather high amount of Pinus sibirica pollen, which can vary from 10.4 to $22.3 \%$ (Fig. 1). The increased amount of Pinus sibirica pollen in these open treeless high mountain areas can be explained by long distant tree pollen brought to open tops of mountains by winds from north located (in $200 \mathrm{~km}$ ) mountain forests of Altai Mountains.

Tannu-Ola Ridge from the south and from the north is surrounded by steppe. Spruce-larch mountain forests with admixture of Siberian pine and patches of steppe vegetation spread on tops of Tannu-Ola mountain range. These mountains extend in latitudinal direction in the most south of Tyva Republic between Tyva steppe and Mongolia steppe in Uvs-Nur hollow. As a result of this, pollen spectra from Tannu-Ola spruce-larch forest is rather specific. It contains a lot of Artemisia pollen together with tree pollen of Pinus sibirica, Picea obovata and Larix (Fig. 1). The

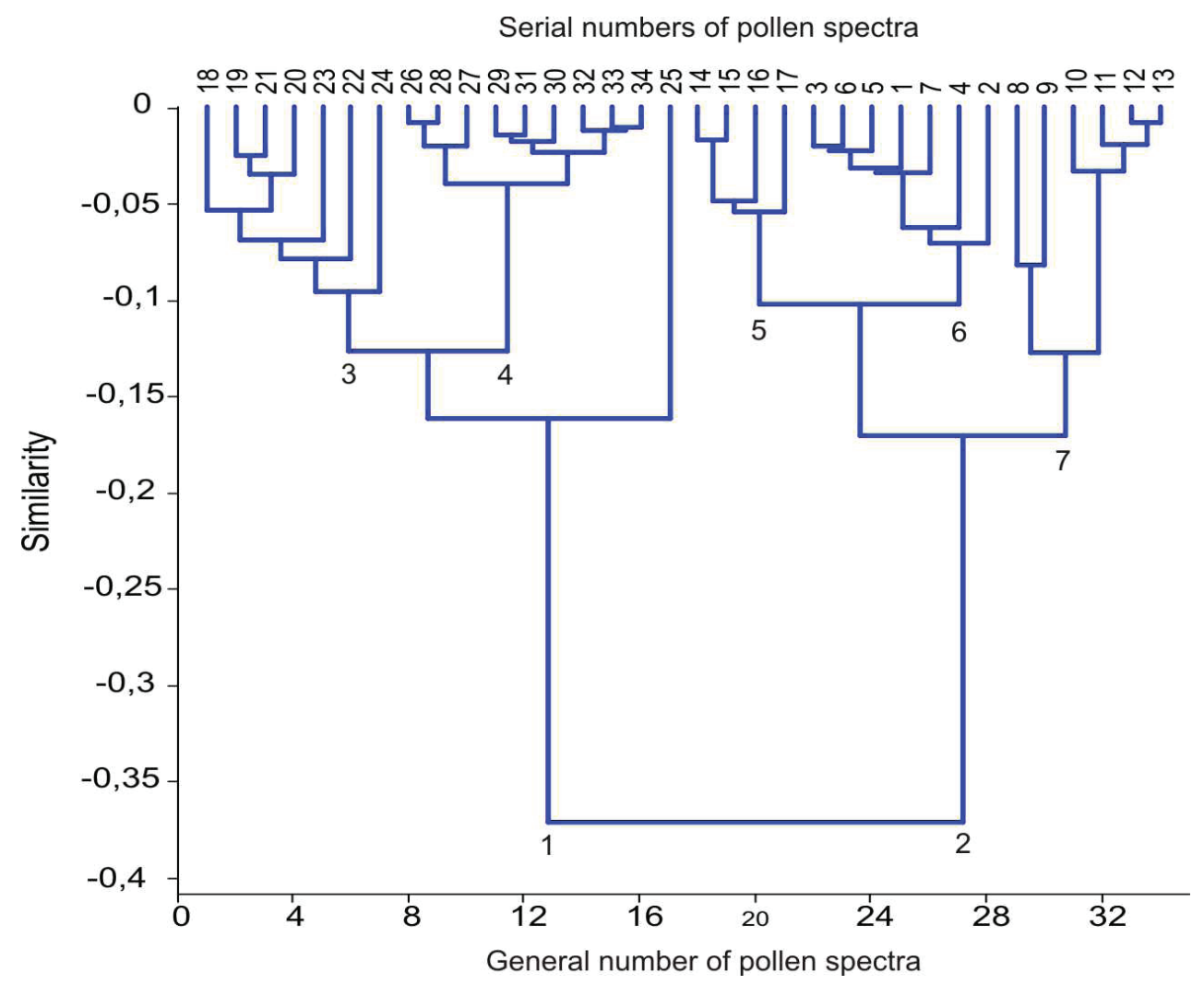

Figure 2. Cluster tree of surface pollen spectra from Tyva and Khakassia republics built by unconstrained cluster analysis 
increase of spruce pollen is not substantial and vary from 3.7 to $7.4 \%$, but quite notable, because of not in steppe pollen spectra nor in high mountain pollen spectra we don't found such amount of spruce pollen. Actually this type of pollen spectra is very similar with pollen spectra found in Glacial and Late Glacial sediments from Europe and Western Siberia. It is considered that this Late Glacial type of pollen spectra have no analogues in modern vegetation on the Earth. It seems that on ridges of TannuOla Mountains in Tyva Republic still exists this relic type of vegetation wide spread in Eurasia during Glacial time.

In the pollen samples of north located Khakassian meadow and grass steppe (more humid variant of steppe) dominate pollen of grasses (Poaceae) and in very small amount present Artemisia pollen. Pollen spectra of Khakassian meadow steppe clearly differ also by increased amount of tree birch pollen (Betula pendula) and Scot's pine (Pinus sylvestris). The last is caused by influence of north located birch forest-steppe of Western and Central Siberia and pine forests of mountain piedmonts.

Sayan Mountains in the south are bounded by Tyva steppe and in the north - by south Khakassian steppe. But unlike to Tannu-Ola Ridge the Sayan mountain taiga is much more vast and dense with humid local climate. As a result of this in pollen spectra of Sayan mountain forest predominate tree pollen of Pinus sibirica and Pinus sylvestris, but pollen of Artemisia present in very small amount. An amount of pollen of mesophilous coniferous such as Abies sibirica and Picea obovata is also increased reaching $2.2-8.4 \%$ and $0.3-1.8 \%$ respectively.

Cluster analyses supports this grouping (Fig. 2). The right branch of cluster tree (cluster 2) includes pollen spectra of predominantly open landscapes (steppe and high mountain vegetation), the left branch (cluster 1) - predominantly forest and forest-steppe pollen spectra. Cluster 6 with serial numbers of spectra 1-7 marks pollen spectra of dry Tyva steppe. Pollen spectra of Tyva high mountain steppe are grouped in neighboring cluster 7 with serial numbers of samples 8-13 located in right corner of cluster tree (Fig. 2). Cluster 5 of Tannu-Ola spruce-larch forest pollen spectra also belongs to right branch of cluster tree because of abundant Artemisia pollen. Cluster 4 of surface pollen spectra collected in mountain taiga of Western Sayan Mountains is very well allocated in left branch of cluster tree (serial numbers of samples 26-34). Three additional samples from mountain taiga we used for cluster analysis and they belong also to this cluster. Cluster 4 of pollen spectra collected in Khakassian meadow and grass steppe is located in right corner of cluster tree. So grouping of contemporary spore-pollen spectra from Khakasia and Tyva by cluster analysis revealed the same types of pollen spectra, but it was more formal than visual grouping. As a result of this, pollen spectra of Khakassian steppe was classified as forested landscape and pollen spectra of Tannu-Ola spruce-larch forest - as open landscape due to strong influence of neighboring vegetation zones on formation of pollen spectra. This says about need of caution in using of formal methods in estimation of contemporary and fossil spore-pollen spectra. All available meta data should be used during interpretation of pollen data. Only with use of it we can see that modern spore-pollen spectra from mountain areas of southern Siberia reflect appropriately the existing vegetation types.

\section{Acknowledgements}

Research was performed with financial support of budget theme of Institute of monitoring of climatic and ecological systems SB RAS and grant № 17-55-52020/MHT_a of Russian Foundation of Basic Research.

\section{References}

Caňellas-Bolta N., Josep V.R. \& Mercade V.A., 2009, Modern pollen-vegetation relationships along an altitudinal transect in the central Pyrenees (Southwestern Europe), The Holocene 19(8): 1185-1200.

Guiot J., 1990, Methodology of the last climatic cycle reconstruction from pollen data, Palaeogeography, Palaeoclimatology, Palaeoecology 80: 49-69.

Kunes P., Pelankova B., Chytry M., Jankovska V., Pokorny P. \& Petr L., 2008, Interpretation of the last-glacial vegetation of eastern-central Europe using modern analogues from southern Siberia, Journal of Biogeography 35: 2223-2236.

Nakagawa T., Tarasov P.E., Nishida K., Gotanda K. \& Yasuda Y., 2002, Quantitative pollen based climate reconstruction in Japan: application to surface and late Quaternary spectra, Quaternary Science Reviews 21: 327-342.

Overpeck J.T., Webb T. III \& Prentice L.C., 1985, Quantitative interpretation of fossil pollen spectra, dissimilarity coefficients and the method of modern analogs, Quaternary Research 23: 87-108.

Prentice C., Guiot J., Huntley B., Jolly D. \& Cheddadi R., 1996, Reconstructing biomes from palaeoecological data: a general method and its application to European pollen data at 0 and $6 \mathrm{ka}$, Climate Dynamics 12: 185-194. DOI: 10.1007/BF00211617 